\title{
Management of superior mesenteric arteriovenous fistula after small bowel resection 20 years previously: Endovascular treatment
}

\author{
Lingjun Liu $\mathrm{MD}^{1,2}$, Yang Yu MD², Xiaodong Jin $\mathrm{MD}^{3}$, Ziqiang Wang MD PhD ${ }^{4}$, Xiao Li MD PhD ${ }^{1,2}$
}

\begin{abstract}
$\mathrm{A}^{59}$ 59-year-old man was admitted to the West China Hospital (Sichuan, China) with recurrent abdominal pain and diarrhea. The patient had undergone a resection of the small bowel due to small intestinal bleeding caused by an ulcer 20 years previously and had no history of trauma. Physical examination revealed stable vital signs, but there was tenderness in the area of the epigastrium radiating to the back without muscle tension and rebound pain. Laboratory tests revealed hemoglobin, white blood cell, total bilirubin, prothrombin time, albumin and creatinine levels of $97 \mathrm{~g} / \mathrm{L}, 18.65 \times 10^{9} / \mathrm{L}, 53 \mathrm{umol} / \mathrm{L}$, $12.0 \mathrm{~s}, 34.1 \mathrm{~g} / \mathrm{L}, 112 \mu \mathrm{mol} / \mathrm{L}$, respectively. Computed tomography (CT) angiography of the abdomen and pelvis revealed marked enhancement of the superior mesenteric vein $(3.1 \mathrm{~cm}$ in diameter $)$ in the arterial phase, the fistula of the neck between the superior mesenteric artery and the superior mesenteric vein $(0.9 \mathrm{~cm}$ in diameter $)$, the engorgement of the intestinal walls and mesentery, and abdominal ascites (Figure 1). Endovascular treatment was implemented in the hybrid operating room. If unsuccessful, open surgery would immediately follow. Superior mesenteric angiography demonstrated a superior mesenteric arteriovenous fistula (SMAVF) in accord with CT (Figure 2). Embolization of the fistula was performed with multiple $8 \mathrm{~mm}, 10 \mathrm{~mm}$ and $12 \mathrm{~mm}$ coils deployed at the neck of the SMAVF, respectively. An additional angiogram showed no opacification of the SMAVF (Figure 3). After the procedure, the patient was monitored carefully for any evidence of bowel ischemia. During the next several days, the patient's abdominal pain disappeared and the initial watery diarrhea gradually resolved. Confirmation of these findings was obtained by ultrasound with no evidence of portal hypertension. At the three-month follow-up, the patient was in satisfactory condition and had no symptoms of bowel ischemia.
\end{abstract}
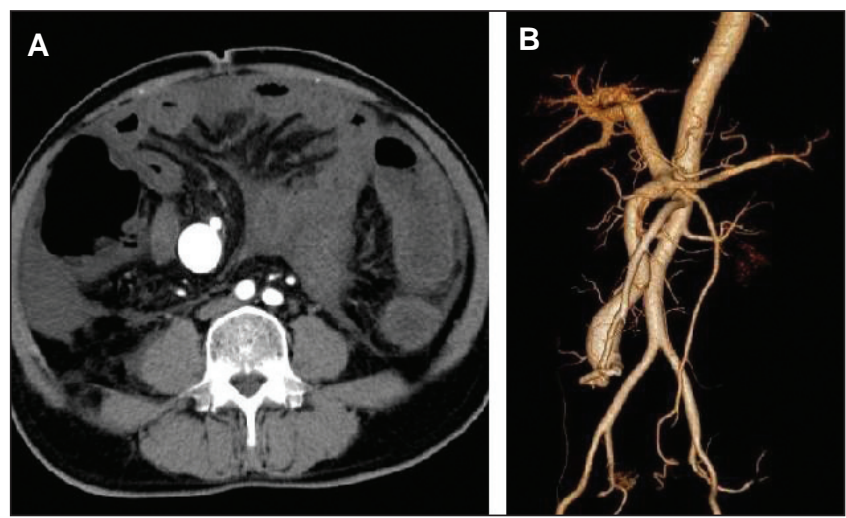

Figure 1) Computed tomography angiography. A Axial view showing the superior mesenteric vein with marked enhancement in the arterial phase and aneurismal dilation. B Volume-rendered computed tomography showing the fistula between the superior mesenteric artery and the superior mesenteric vein

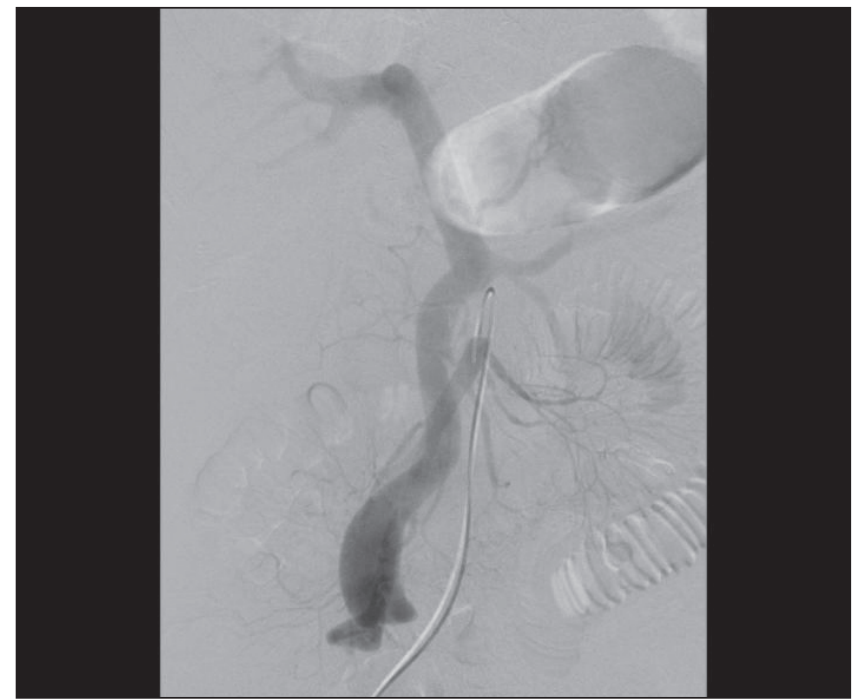

Figure 2) Superior mesenteric angiogram showing the distal superior mesenteric artery with direct shunting of contrast into the superior mesenteric vein, which is in accord with the volume-rendered computed tomography shown in Figure 1 B

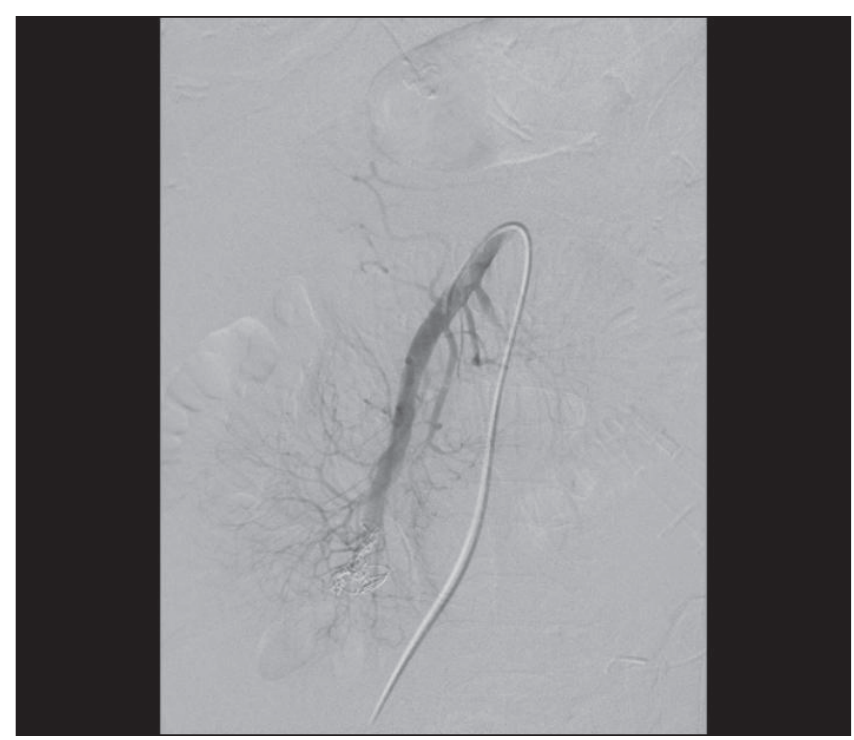

Figure 3) Postembolization angiogram. The fistula from the distal superior mesenteric artery to the superior mesenteric vein has been occluded with multiple $8 \mathrm{~mm}, 10 \mathrm{~mm}$ and $12 \mathrm{~mm}$ coils. An addirional angiography shows no further opacification of the superior mesenteric arteriovenous fistula

${ }^{1}$ Department of Radiology; ${ }^{2}$ Department of Gastroenterology and Hepatology; ${ }^{3}$ Department of Intensive Care Unit; ${ }^{4}$ Department of Gastrointestinal Surgery, West China Hospital, Sichuan University, Chengdu, China

Correspondance: Prof Xiao Li, Department of Gastroenterology and Hepatology, West China Hospital, Sichuan University, 37 Guoxue Lane,

Chengdu 610041, China. Telephone 86-138-8175-5965, fax 86-028-8558-2944, e-mail simonlixiao@gmail.com

Received for publication August 26, 2012. Accepted September 9, 2012 


\section{DISCUSSION}

The first arteriovenous fistula was reported in 1947, but documented SMAVFs are extremely rare $(1,2)$. The formation of SMAVFs is usually due to trauma or iatrogenic injury, such as penetrating trauma, ileal resection, appendectomy, hemicolectomy and sigmoidectomy (1). In the present case, it was most likely the a result of iatrogenic vascular injury during resection of the small bowel 20 years previously. The clinical manifestations of SMAVF may vary from the asymptomatic carrier state to a delayed presentation of abdominal pain, anorexia, diarrhea, gastrointestinal hemorrhage, signs of portal hypertension and even congestive heart failure (3). Treatment options for SMAVF

\section{REFERENCES}

1. Wu C-G, Li Y-D, Li M-H. Post-traumatic superior mesenteric arteriovenous fistula: Endovascular treatment with a covered stent. J Vascul Surg 2008;47:654-6.

2. White RD, Ananthakrishnan G, Bhat R. Arteriovenous fistula of a colic branch of the superior mesenteric artery: Endovascular therapy. Cardiovasc Intervent Radiol 2010;3:866-9.

3. Weinstein D, Huler A, Belinki A, et al, Superior mesenteric artery to superior mesenteric vein arteriovenous fistula presenting as abdominal pain and gastrointestinal bleeding 3 years after an include surgical intervention (4), and endovascular management such as coil embolization (5) and covered stentgrafts (1). Before treatment, CT angiography can evaluate the position and the size of fistula, the severity of portal hypertension and intestinal ischemia. In our case, coil embolization was used to avoid greater risks in open surgery. Endovascular treatment for SMAVF may be an effective and safe therapeutic option.

ACKNOWLEDGMENT: This study was supported by The National Natural Science Foundation of China (Grant no. 30770984, 81171444).

abdominal gunshot wound: Report of a case and review of the literature. J Trauma 2009;66:E13-6.

4. Francois F, Thevenet A. Superior mesenteric arteriovenous fistula after ileal resection. Ann Vascul Surgery 1992;6:370-2.

5. De Gregorio MA, Gimeno MJ, Medrano J, Schönholz C, Rodriguez J, D'Agostino H. Ileocolic arteriovenous fistula with superior mesenteric vein aneurysm: Endovascular treatment. Cardiovasc Intervent Radiol 2004;27:556-9.

The Canadian Journal of Gastroenterology is now considering a limited number of submissions for IMAGE OF THE MONTH. These are based on endoscopic, histological, radiological and/or patient images, which must be anonymous with no identifying features visible. The patient must consent to publication and the consent must be submitted with the manuscript. All manuscripts should be practical and relevant to clinical practice, and not simply a case report of an esoteric condition. The text should be brief, structured as CASE PRESENTATION and DISCUSSION, and not more than 700 words in length. A maximum of three images can be submitted and the number of references should not exceed five. The submission may be edited by our editorial team.

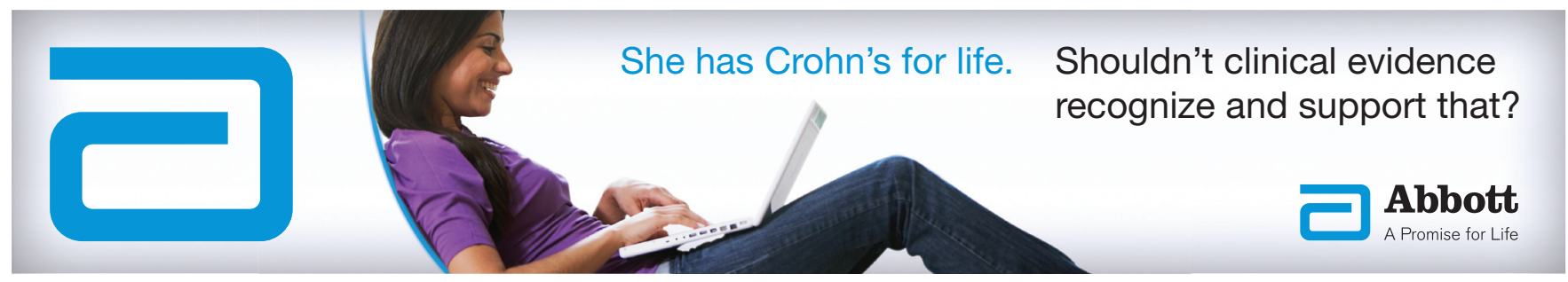




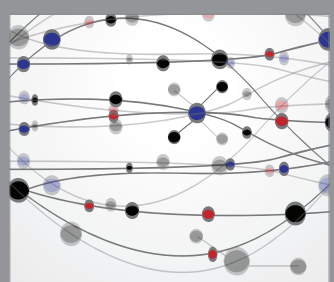

The Scientific World Journal
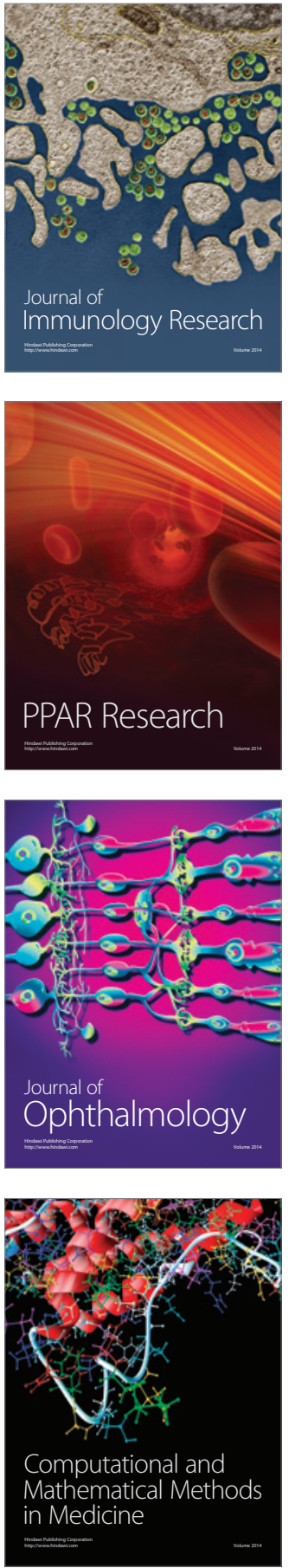

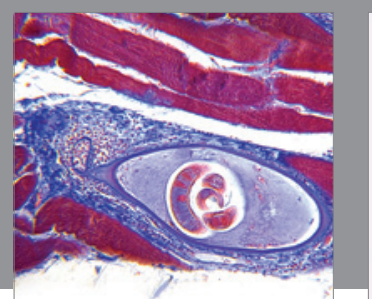

Gastroenterology Research and Practice

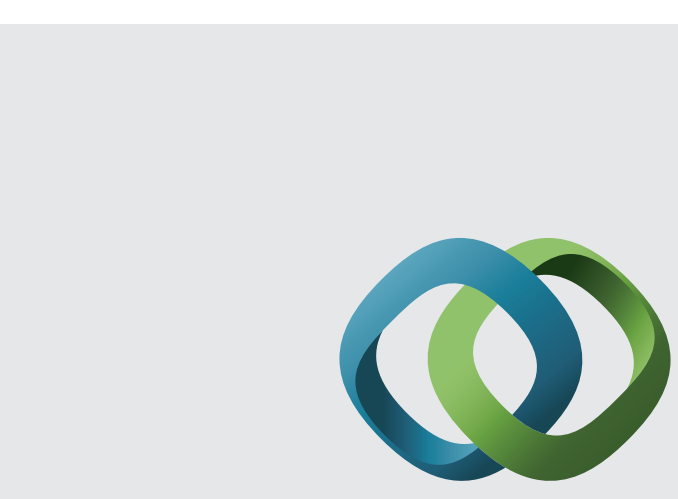

\section{Hindawi}

Submit your manuscripts at

http://www.hindawi.com
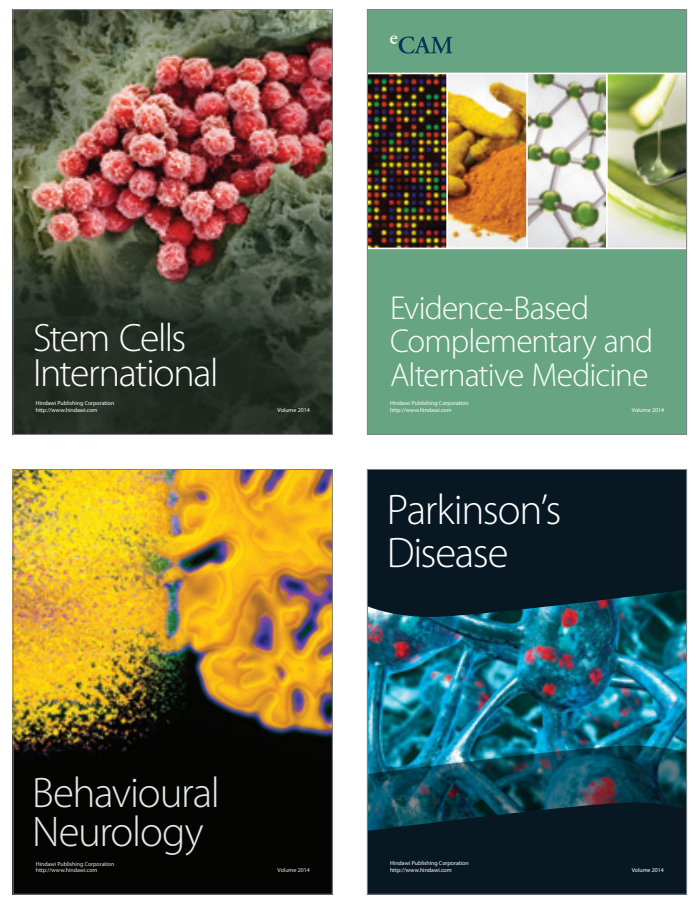
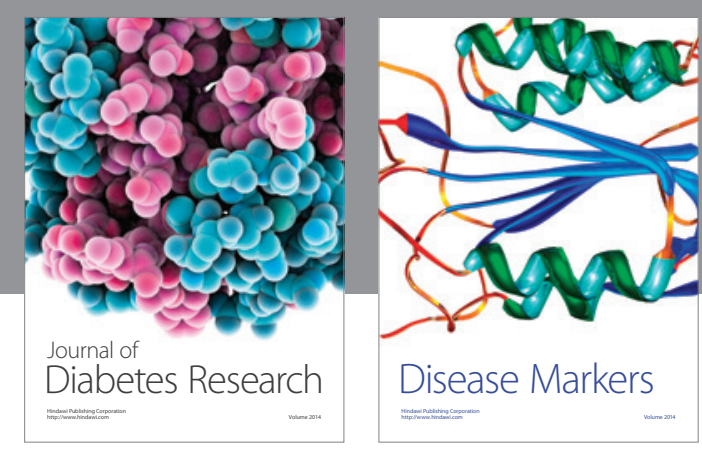

Disease Markers
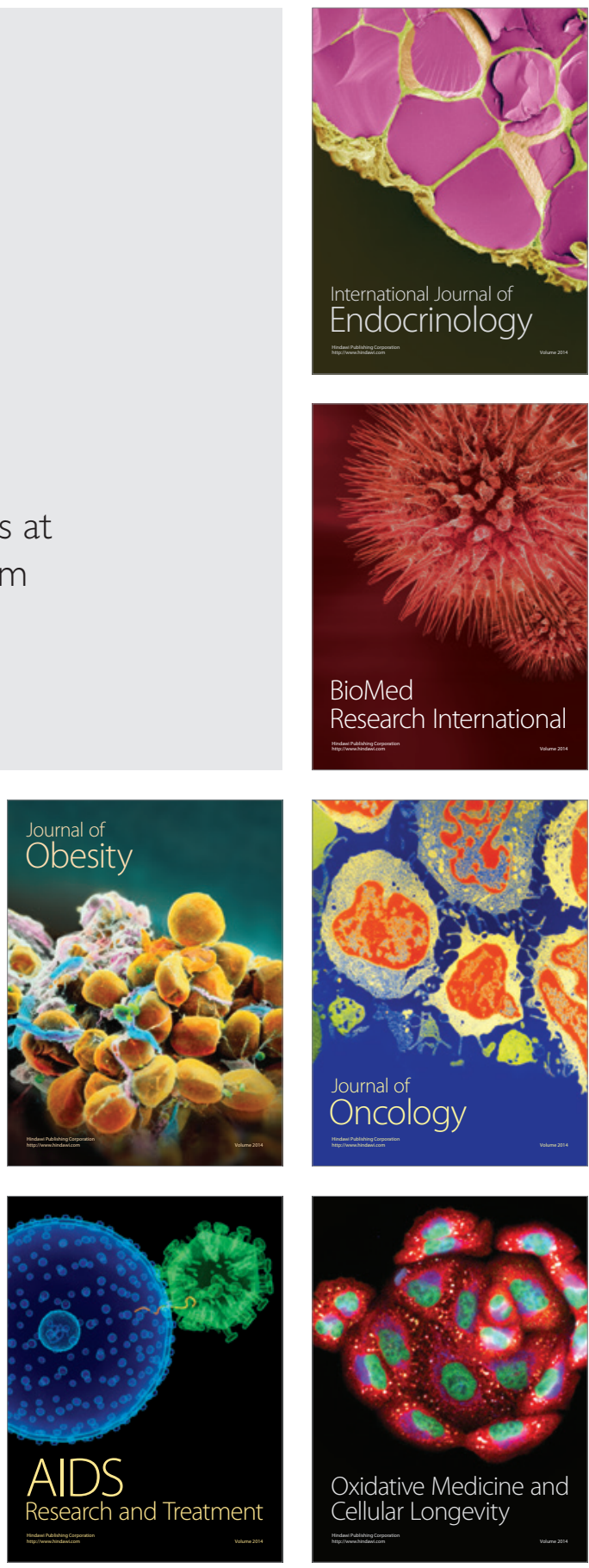